\title{
Neue Version 1.04 TARMED tritt am 1. April 2007 in Kraft
}

Die neue Tarifversion 1.04 hat gegenüber ihrer Vorgängerversion verschiedene Änderungen erfahren:

- neue Tarifpositionen wurden geschaffen;

- diverse Tarifpositionen wurden gestrichen;

- einige qualitative Dignitäten wurden gestrichen.

Nützliche Informationen stehen auf unserer Homepage für Sie bereit: www.fmh.ch / Unsere Dienstleistungen / Dignität

\section{TARMED 1.04: la nouvelle version du tarif entre en vigueur le $1^{\text {er }}$ avril 2007}

La nouvelle version 1.04 du TARMED présente différentes modifications par rapport à la version précédente:

- de nouvelles positions tarifaires ont été créées;

- diverses positions tarifaires ont été supprimées;

- quelques valeurs intrinsèques qualitatives ont été supprimées.

Vous trouverez des informations utiles sur notre site internet: www.fmh.ch / Nos prestations / Valeur intrinsèque 